\title{
OPERATIONAL EXCELLENCE FOR SYSTEMS ENGINEERING (OESE): STATE OF ART
}

\author{
Kokolo, Joseph; \\ Eynard, Benoit \\ Université de Technologie de Compiègne
}

\begin{abstract}
Operational Excellence (EO) is increasingly present in scientific and managerial news. Increasing competition, increasingly uncertain events, demands customers and society increasingly pressing, the evolution of systems towards cyber physics systems, push organizations to adapt their engineering methodologies. Excellence operational (EO) is one of the answers proposed by the scientific literature to make engineering organizations more flexible, more responsive, more efficient and therefore more competitive. In this article, we share a state of the art of operational excellence (EO) in system engineering (IS) through its most modern methodologies: the Lean Six Sigma (LSS), Theory of Constraints (TOC) and Agility (A) with an operational approach including social and societal responsibility via the Quality-Cost-Delay-Security-Environment (QCDSE). We finish by sharing four assumptions that will serve as a basis, in our future contribution, to propose a synergy solution to implement an Operational Excellence approach in systems engineering organizations.
\end{abstract}

Keywords: Industry 4.0, Systems Engineering (SE), Design methodology, Collaborative design, Optimisation

\section{Contact:}

Kokolo, Joseph

UNIVERSITE DE TECHNOLOGIE DE COMPIEGNE

LABORATOIRE DE MECANIQUE ROBERVAL

France

joseph_kokolo@hotmail.com 


\section{INTRODUCTION}

The design of system engineering takes a significant technological way in recent years. We are gradually moving towards IoT systems, inter-connected with an exponential complexity without to measure all the possible impacts. One thing is sure, our engineering methodologies will have to adapt to this reality in order to remain efficient and competitive. The scientific literature shows us that only adaptive, learning and inclusive methodologies can effectively respond to constantly changing issues. As such, Operational Excellence (OE), which is a scientific, managerial, operational, global, continuous improvement approach, should enable engineering organizations to continuously adapt to this and to the future changes. A large number of works and books propose methodologies to adopt an OE approach for high performance and competitive organizations (Oakland, 2001) (Burton and Pennotti, 2003) (Gershon, 2010) (Collins, 2001) (Geracie and Eppinger, 2013) (Girard, 2017) (Jombart, 2016) (Rossi et al. 2016) (Meyer, 2014) (Ghavami, 2008) (Baxter, 2015). These works have inspired us to achieve this paper. The OE approach was born at the end of the 19th century, in American industry, with Taylorism. Henry Ford then introduced the notion of continuous movement in the 1920s. Customer satisfaction appeared around the 1930s and 1940s, thanks to Alfred Sloan. Later, Edward Deming, between 1945s-1960s, was the first to introduce the notion of statistics in quality control, and he gave birth to the wheel of continuous improvement (Jombart, 2016). OE is a recent term that encompasses all the methodologies used to continuously improve the organizations performance.

In the following lines, we propose you a state of the art of $\mathrm{OE}$ through its most current methodologies: Lean Six Sigma (LSS), Theory of Constraints (TC) and Agility (A). As OE is a recent term, we propose a state of the art adapted to the growing interest of scientific research on this problematic. We introduce the subject with a statistical analysis before discussing the definition and characteristics of each of current OE methodologies. Then, we will talk about the complementarity of these current methodologies through synergy solutions: The TLS (Theory of Constraints-Lean-Six Sigma) and the LAS (Lean Six Sigma-Agility-System Engineering). We will share the four assumptions which will allow us to propose our synergy solution for the engineering of systems (Hehenberger et al. 2016). Figure 1, below, is an adapted version of (Morris, 2021). It illustrates the evolution of current OE methodologies over time. We have chosen to include the history of systems engineering to well contextualize for our works.

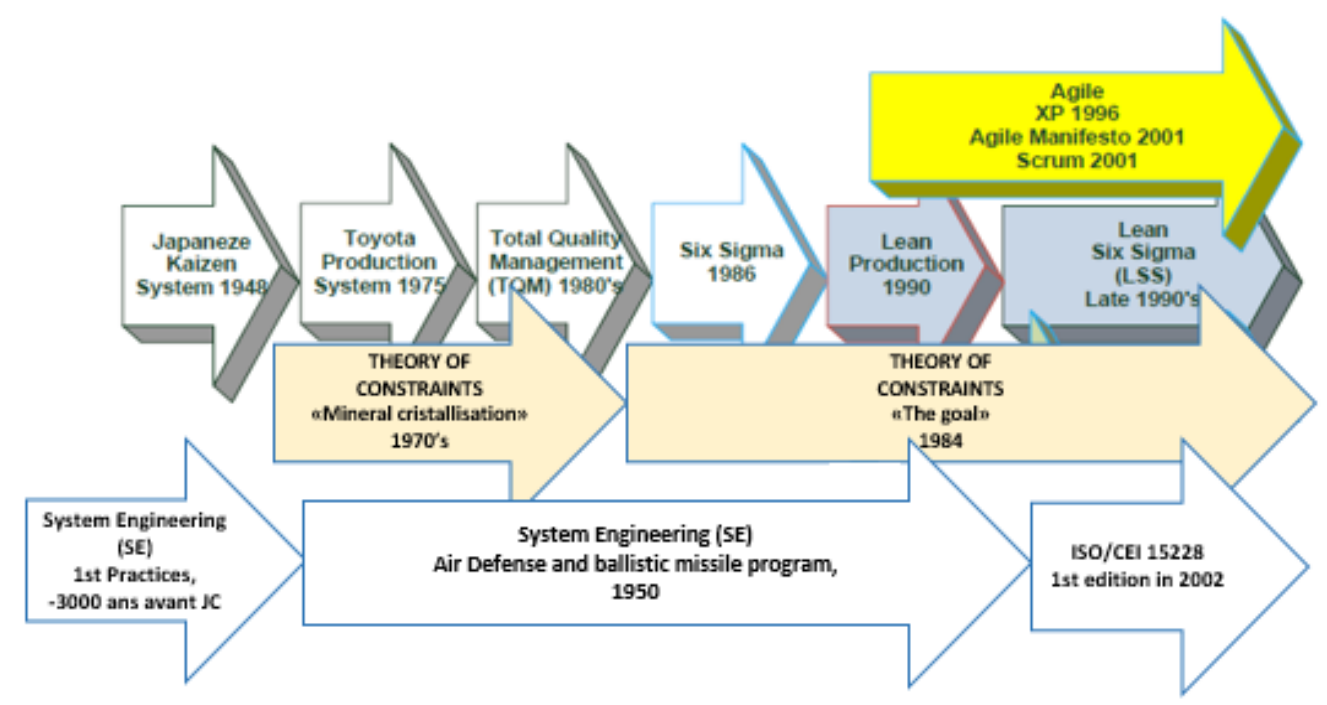

Figure 1: History of comparative developments of systems engineering and operational excellence. 


\section{STATE OF ART}

\subsection{Some Data}

In this section, we present some statistical data highlighting the growing importance of current $\mathrm{OE}$ methodologies in the scientific literature. (Badwe and Erkan, 2018), have performed a statistical analysis of academic publications on Lean, Six Sigma, Lean Six Sigma (LSS) and agility (A) after searching for articles with the Six Sigma, Lean, Lean six Sigma and Agile "Keyword" in the primary subjects (title, abstract, keywords) on the ISI Web of Knowledge databases. This statistical analysis s construct with respect to the forty six papers published over a period of more than ten years, from 2003 to 2017. It demonstrates, factually, the growing importance of current OE methodologies in the systems engineering. Figures 2, 3, 4 are graphic transcriptions of the data obtained through this analysis. They are complementary and have been extracted from the work of (Badwe and Erkan, 2018).

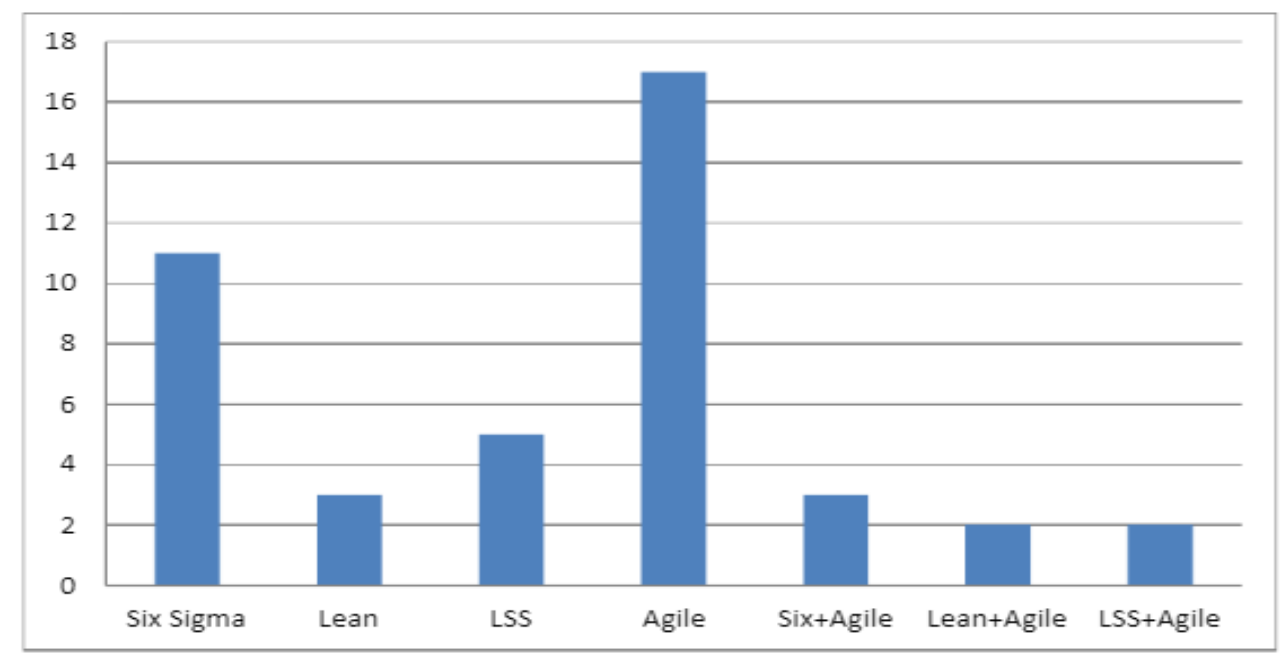

Figure 2: Occurrence of current methodologies discussed in academic publications.

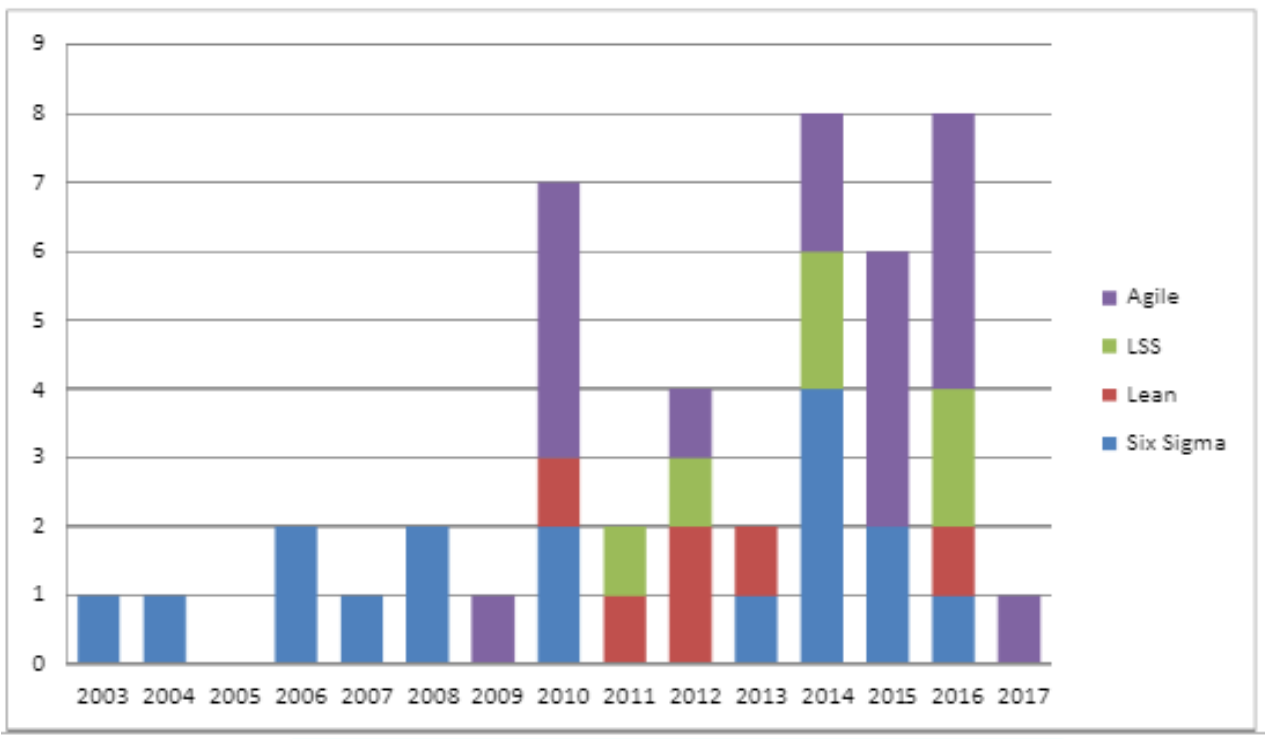

Figure 3: Allocation of publications on the current methodologies discussed by chronological order. 


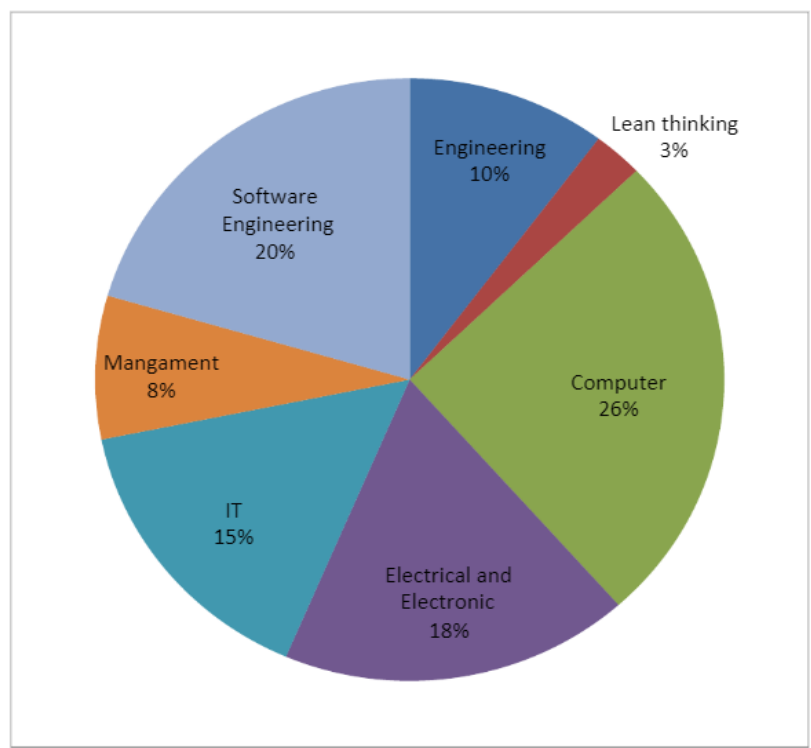

Figure 4: Allocation of academic publications by field of systems engineering.

The bibliographical study made by (Badwe and Erkan, 2018) and our professional experiences in systems engineering, have pushed us to orientate our works towards these current OE methodologies. In the following section, we will focus on their definitions, their characteristics, their complementarities and their antagonisms.

\subsection{Definitions}

Operational Excellence (OE). (Girard, 2017) defines OE as an element of the corporate culture aimed at promoting behaviours and implementing an organization and tools to continuously improve an organization's performance. In his definition, Girard highlights five (5) key concepts: culture, behaviours, organization, tools and performance continuous improvement. ICulture requires considering $\mathrm{OE}$ as a long-term objective that touches the company's DNA. Behaviours require that the implementation of the culture be translated into specific behaviours that are in line with the company's overall business. Organization requires that the culture put in place and the behaviours adopted be identifiable within an organization. The tools will be necessary for the deployment and the application of this new corporate culture. Performance continuous improvement is the goal of OE. The long-term goal is to continually drive the company to a high level of performance and competitiveness. To Girard's managerial definition, (Jombart, 2016) gives an operational, complementary, more visual definition. Jombart's definition highlights the operational imperatives of an organization: to satisfy the client, involve the stakeholders, make continuous progress, valorise people and share the vision. Through their definitions, (Girard, 2017) and (Jombart, 2016) define the framework of the objectives that an effective $\mathrm{OE}$ approach must target over time. We have based on these identified objectives to propose the adoption of an operational assessment tool with five dimensions: QCDSE (Quality-CostDelivery-Safety-Environment), which we define below in a dedicated section.

In the scientific literature, a significant number of scientific works associate OE with systems engineering under the name of System Operational Excellence (SOE). The SOE approach is used for the design of complex systems. (Verma et al. 2003) consider that the system operational excellence concerns the systems engineering and the systems integration with the aim of achieving the best possible compromise between system performance, system availability, process efficiency and total system costs. They established the following wording to reflect the cause-and-effect relationship of these different factors for system operational excellence.

$$
S O E=f(F P, S A, P E, C l f c)
$$

$\mathrm{SP}=$ System Performance $\mathrm{SA}=$ System Availability $\mathrm{PE}=$ Process Efficiency $;$ Clfc $=$ Cost of lifecycle

Verma et al. have established an SOE model that highlights, in the detail, the various factors to be optimized for a successful system organization (Figure 5). 


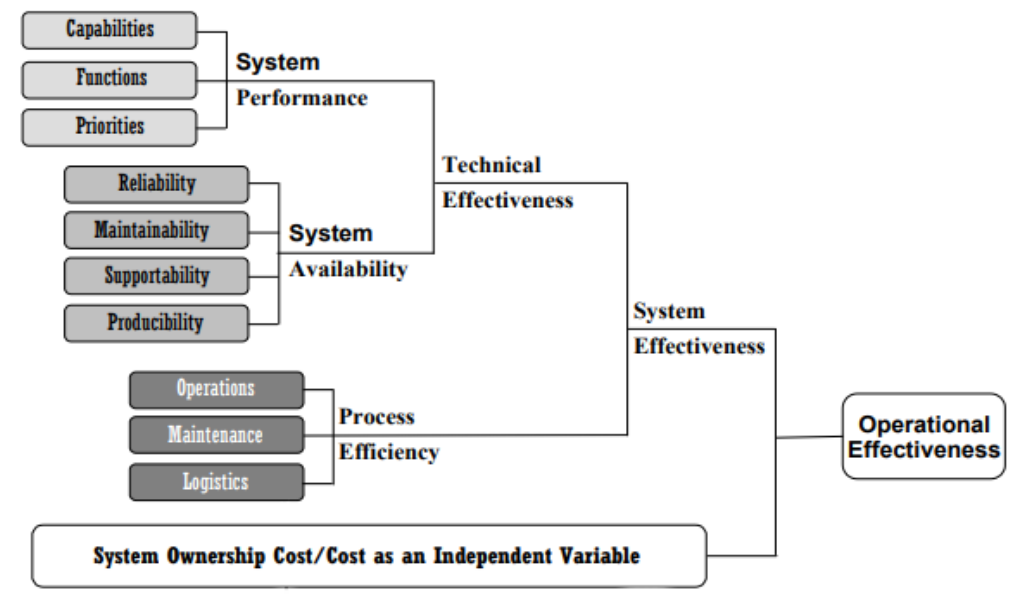

Figure 5: SOE: Model proposed by (Verma et al. 2003).

The SOE is useful for complex engineering organizations (defense, aeronautics). However, it doesn't allow to take into account social and societal stakes of current engineering organizations. Therefore, we will focus on the current OE methodologies as detailed in the following lines.

Lean Six Sigma (LSS). Lean Six Sigma is the junction of two approved methodologies: Lean and Six Sigma. It integrates all the strong points of both methodologies and presents all their advantages. Since its introduction by Georges (2002), LSS has spread around the world as a tool to improve the performance of organizations. Table 1 presents the complementary advantages of Lean management and Six Sigma (Nave, 2002) (Volck, 2009) (Munteanu, 2017) (Pacheco, 2015) (Rossi et al. 2016).

Table 1. Lean Six Sigma: Major features

\begin{tabular}{|c|c|c|c|}
\hline Methodology & Six sigma & Lean & Lean six sigma \\
\hline Proposed in & 1980 & 1990 & 2002 \\
\hline Goal & $\begin{array}{l}\text { - Stabilize - } \\
\text { Reduce variability } \\
\text { (Satisfying customer } \\
\text { requirements) }\end{array}$ & $\begin{array}{l}\text { - Simplify - } \\
\text { Remove waste } \\
\text { (Improving } \\
\text { productivity) }\end{array}$ & - Stabilize and Simplify - \\
\hline Tools & $\begin{array}{l}\text { DMAIC, DMADV, } \\
\text { DFSS. } \\
\text { (statistical measures of } \\
\text { variability) }\end{array}$ & $\begin{array}{l}\text { Ishikawa Diagram, } \\
\text { 5W, 5S, Kanban, } \\
\text { SIPOC, VSM, Poka } \\
\text { Yoke (visual } \\
\text { measures). }\end{array}$ & $\begin{array}{l}\text { Junction of Lean and Six } \\
\text { Sigma tools }\end{array}$ \\
\hline Focus & Problem & Flux & Performance improvement \\
\hline Implementation & Bit difficult & Easy & Bit difficult \\
\hline Direct results & $\begin{array}{l}\text { Standardization of } \\
\text { processes }\end{array}$ & $\begin{array}{l}\text { Reduction of flow } \\
\text { duration }\end{array}$ & \multirow{2}{*}{$\begin{array}{l}\text { Combined } \\
\text { Lean and Six Sigma } \\
\text { results. }\end{array}$} \\
\hline Indirect results & $\begin{array}{l}\text { Less variation, less } \\
\text { inventory, performance } \\
\text { Measurement } \\
\text { (variability), quality } \\
\text { improvement. }\end{array}$ & $\begin{array}{l}\text { Less waste, fast } \\
\text { throughput, less } \\
\text { inventory, performance } \\
\text { measurement (flow), } \\
\text { quality improvement. }\end{array}$ & \\
\hline Limits & $\begin{array}{l}\text { System interactions not } \\
\text { taken into account, } \\
\text { individual } \\
\text { improvement of each } \\
\text { process. }\end{array}$ & No statistical analysis. & $\begin{array}{l}\text { Combined Lean and Six } \\
\text { Sigma limits }\end{array}$ \\
\hline
\end{tabular}

Theory of Constraints (TC). The theory of constraints has been initiated by (Goldratt, 2014). In his book, he proposes a methodology to manage the inevitable bottlenecks in the execution of tasks in a systemic organization. Goldratt considers that the presence of bottlenecks is inevitable for any activity. Instead of limiting the constraints present in an organization, it is better to identify them and execute all tasks according to these constraints in order to maximize system performance. (Gershon, 2010) (Nave, 2002) and (Pacheco, 2015), in their respective works, highlight the essential characteristics of the TC. We have been inspired by these works to propose Table 2 . 
Table 2. Theory of constraints: Major features.

\begin{tabular}{|l|l|}
\hline Methodology & Theory of Constraints \\
\hline Proposed in & 1984 \\
\hline Goal & $\begin{array}{l}\text { - Synchronize - } \\
\text { Manage bottlenecks } \\
\text { (Reduce the impact of constraints) }\end{array}$ \\
\hline Tools & $\begin{array}{l}\text { Nine (9) rules of the TOC } \\
\text { (statistical and non-statistical tools) }\end{array}$ \\
\hline Focus & Constraint \\
\hline Implementation & Difficult \\
\hline Direct results & Fast throughput \\
\hline Indirect results & $\begin{array}{l}\text { Less cost overshoot, less inventory, performance measurement (throughput), } \\
\text { quality improvement }\end{array}$ \\
\hline Limits & $\begin{array}{l}\text { Less known methodology, Minimized team contribution, Non-valued data } \\
\text { analysis, Abstraction of part of the organization to the benefit of constraint } \\
\text { management. }\end{array}$ \\
\hline
\end{tabular}

Agility (A). Agility is the most current OE approach, it is applied by a large number of organizations (Badwe and Erkan, 2018). In 2001, a group of seventeen software development enthusiasts initiated the Agile Manifesto (Beck et al. 2001): a set of project management practices that aims to be more pragmatic than traditional methodologies. The agile methodology allows to an organization to increase its execution speed, its flexibility to change and to reduce execution costs by focusing on customer satisfaction, collective intelligence, daily team involvement and continuous improvement (Badwe and Erkan, 2018) (Morris, 2012). Table 3 lists the main characteristics of agility. It is extracted from the works of (Badwe and Erkan, 2018) (Morris, 2012) (Munteanu, 2017).

Table 3. Agility: Main features.

\begin{tabular}{|l|l|}
\hline Methodology & Agility \\
\hline Proposed in & 2001 \\
\hline Goal & $\begin{array}{l}\text { - Prioritize - } \\
\text { Schedule and cadence the processing of customer needs } \\
\text { (Satisfy the customer requirements, improving productivity) }\end{array}$ \\
\hline Tools & $\begin{array}{l}\text { Kanban Workflow, scrum approach, Project backlog, sprint backlog, sprint } \\
\text { (iterative and incremental practices) }\end{array}$ \\
\hline Focus & System \\
\hline Implementation & Easy \\
\hline Direct results & Fast design \\
\hline Indirect results & $\begin{array}{l}\text { Transparency, collective intelligence, Reduce any process time and cost } \\
\text { overload, continuous inspection, improve flexibility }\end{array}$ \\
\hline Limits & $\begin{array}{l}\text { Quality often side lined, Less time for documentation, Requires the } \\
\text { customer's availability. }\end{array}$ \\
\hline
\end{tabular}

Systems Engineering. Today's large industrial organizations use systems engineering to design their engineering systems. Service companies are more and more interested in it to drive their organizations in a process continuous improvement. (INCOSE, 2015) define systems engineering as a set of activities that allows to go from an identified need to a validated solution, with a systemic and controlled approach. The systems engineering is a recent science, but its practice is a millennial one. Systems engineering was born in the 1950s in the large organizations of defense, aeronautics, and automobile. As an age-old practice, the builders of the pyramids had thought about a division of activities. The art of erecting these monuments was based on a codified know-how. The questions of logistics had been intuitively integrated, the first pyramids being close to the quarries, the following ones being further away but close to the material transportation routes.

System engineering is governed by three historical standards IEEE 1220, EIS-632 and ISO/IEC 15288. The ISO/IEC 15288 standard has the broadest scope. Its processes cover the entire systems lifecycle, integrating project and organisation processes. Figure 6 is taken from (ISO/IEC 15228, 2002) (INCOSE, 2015) (Blanchard, 2016) to illustrate our orientation. 


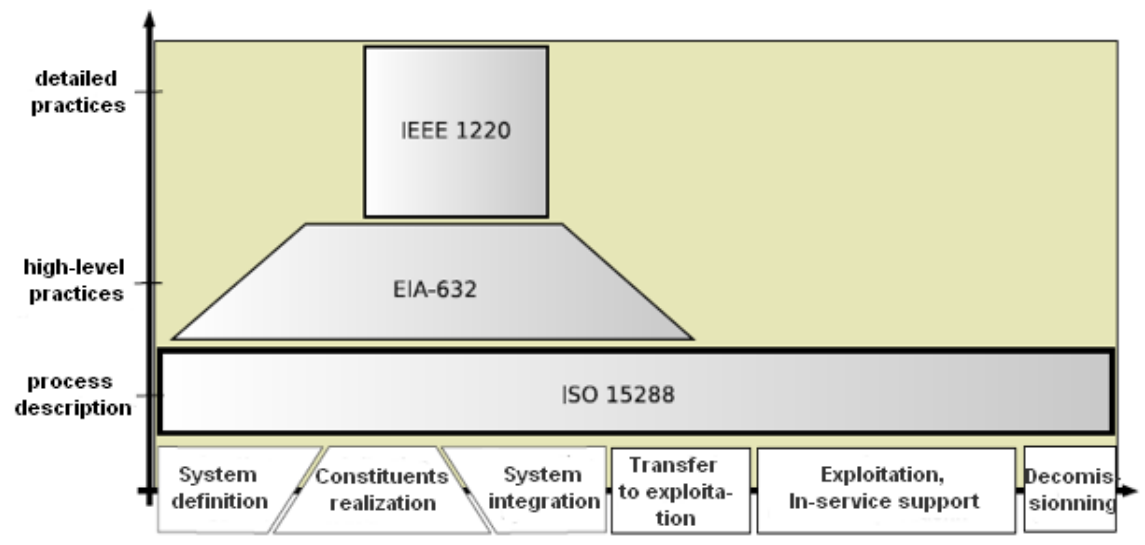

Figure 6: Systems engineering: Existing standards and definition of their perimeter according to the system lifecycle.

In large organizations, the ISO/IEC 15288 systems engineering standard is always associated with complementary methodologies to complete the approach of performance continuous improvement. (Hehenberger et al. 2016), remind us that the complexity of a systems engineering approach depends directly on the complexity of system concerned. In other words, the more complex our system is, the more complex its subsystems are, the more the number and diversity of interfaces increases, and the more the systems engineering approach will have to solve system integration and interaction problems. By causal effect, this increasing level of system complexity will require an evolution of the ISO/IEC 15288 standard and the adoption of one or more new complementary methodologies. We will base on this principles to propose a complementary methodology to the ISO/IEC 15288 for our contributions by taking into account the different types of engineering systems. Figure 7 shows the different types of engineering systems ranging from mechanical systems to IoT systems via embedded systems and cyber physical systems (Hehenberger et al. 2016). The following figure is adapted from an illustration in their paper.

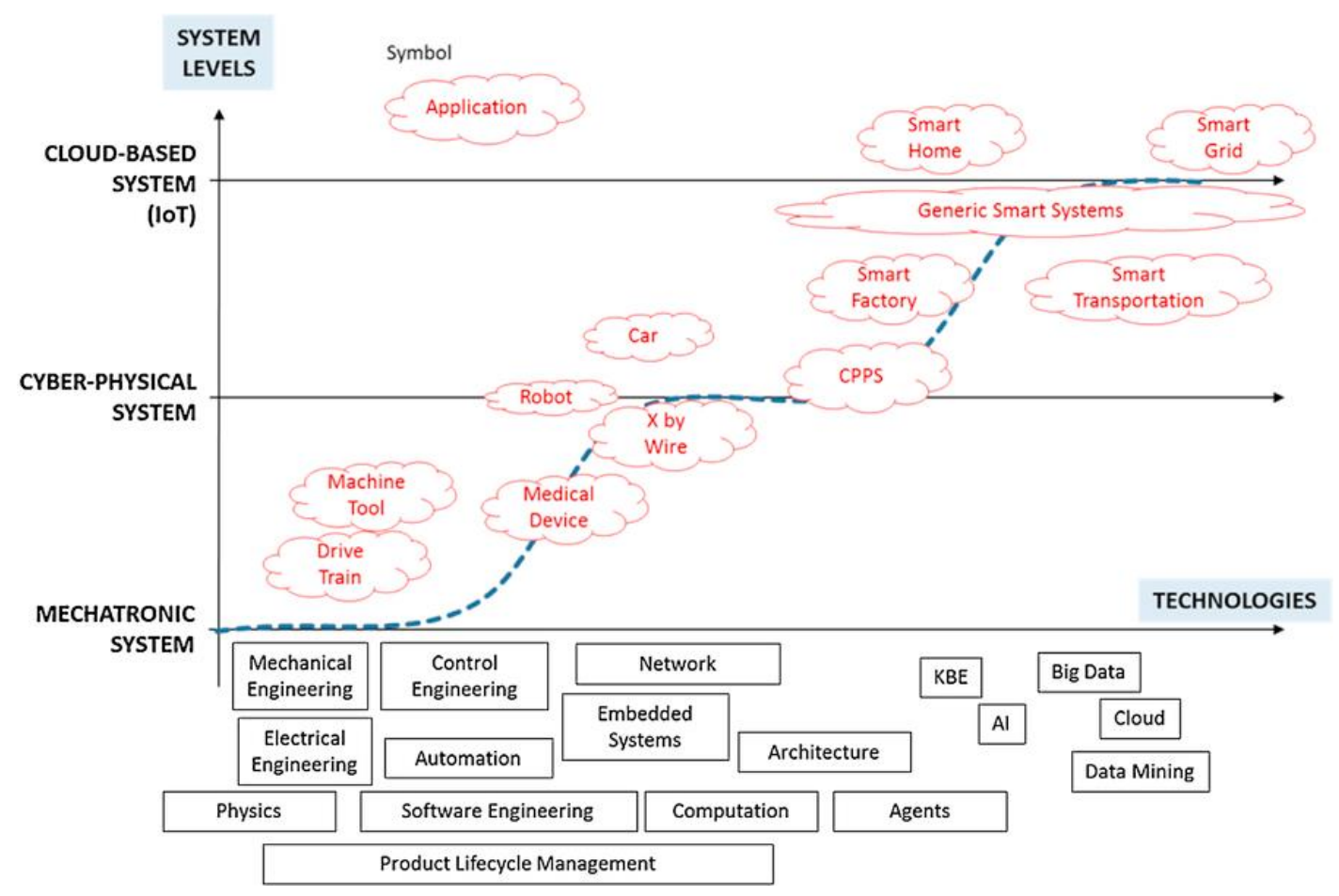

Figure 7: Systems engineering: From mechanical systems to loT systems and cyberphysical systems. 
QCDSE. OE as defined by Girard (2017) at the managerial level and by Jombart (2016) at the operational level, aims to improve the overall performance of an organization. To fulfilled Girard and Jombart requirements; we are looking for the most adequate criteria possible. In the managerial literature, the Quality-Cost-Delivery (QCD) triangle is the most used criteria to evaluate the operational activities of an engineering organization. However, QCD is limited by the absence of the principles of social and societal responsibilities promoted by Jombart. It became clear to us that the QCD triangle needed to evolve towards a more complete definition. Different criteria are proposed by the management and scientist literature for the continuous assessment of high performance organizations (ISO 9000, 2017) (Waal, 2011) (Porter and Tanner, 2003). We have chosen to use fivedimensional criteria (QCDSE) instead of three-dimensional criteria (QCD). The assessment criteria Quality-Cost-Delivery-Safety-Environment is an operational and a managerial tool, suitable for any production organization and, allow to integrate the principles of social and societal responsibility via two additional criteria: safety and the environment. QCDSE allows to evaluate, as a whole, the performance of our future contribution to $\mathrm{OE}$ methodologies. Figure 8 shows the meaning and the targets of each QCDSE criteria. It is an extraction of (Waal, 2011) (Porter and Tanner, 2003).

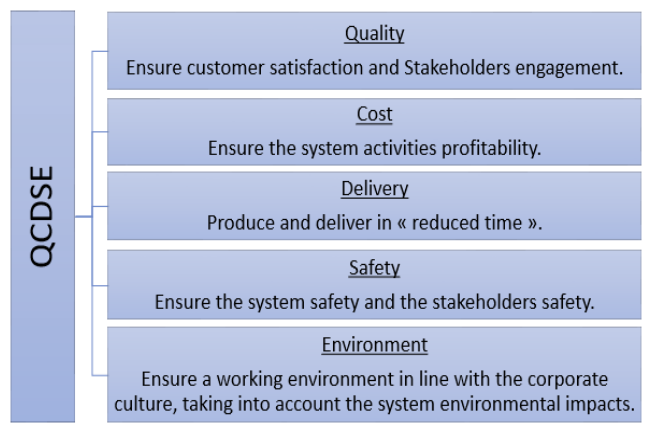

Figure 8: QCDSE: Definition and principles

\section{THE EXISTING SYNERGY SOLUTIONS}

The scientific and managerial literature reports several works on synergy solutions bringing together current OE methodologies (Pacheco, 2015) (Hohmann et al. 2016) (O'Rourke, 2005) (Sreedharan and Raju, 2016) (Huang, 2002) (Gubinelli et al. 2019). Of all the synergy solutions, two solutions are unique for their completeness, their complementarity, and their ability to satisfy (Girard, 2017) and (Jombart, 2016) definitions: the TLS and the LAS.

The solution TLS (Theory of Constraints- Lean- Six sigma). (Hohmann et al. 2016), propose a "meta-methodology" combining Theory of Constraints, Lean and Six Sigma which would use all or a part of each of these methodologies to amplify their effects. They outline a possible deployment approach in two (2) steps. Beforehand, focus on the bottleneck whose identification and exploitation would be possible with the constraint theory. Then, once the bottleneck has been identified, use Lean or Six Sigma tools and methods for efficient exploitation. However, as also emphasized by (Hohmann et al. 2016), it is the responsibility of each organization to adapt the scheduling of the TLS deployment process according to the organization's priority needs. Recommendation confirmed by (Pacheco, 2015).Mayer has demonstrated the applicability of TLS for service companies (Meyer, 2014). However, the TLS solution finds its limit through the theory of constraints, known to be a methodology with a high scientific complexity, difficult to deploy in an organization.

The solution LAS (Lean Six sigma- Agility-Systems engineering). (Morris, 2012), (Cesarotti et al. 2019) propose a Lean Six sigma- Agile synergy solution - Systems engineering methodology (respectively CMMI and PMP). They propose a framework linking the system engineering processes (respectively CMMI and PMP) and the LSS DMAIC approach allowing the execution of systems engineering activities in an environment of continuous improvement of the processes. For each phase of the lifecycle, they recommend the application of Agile methodologies in order to benefit from the contributions of agility. This will promote the installation of a culture of discipline, essential to ensure the deployment and application of the OE approach. (Ghavami, 2008) mentions the applicability of LAS in engineering. He outlines its benefits in performance leading to a continuous search of excellence. Ghavami's works is the closest to the synergy solution that we will propose. 


\section{ASSUMPTIONS FOR AN OPERATIONAL EXCELLENCE LOOP}

The works developed in the previous sections of this paper, allow to consolidate four (4) assumptions that will be the basis for proposing a solution leading to operational excellence:

1. The system engineering process approach: All major industrial organizations use the ISO/IEC 15288 standard processes as their system engineering methodology. (INCOSE, 2015) provide tools, practices, methodologies for any organization, to adopt system engineering processes. Our first assumption will be to consider that organizations use systems engineering processes to design their systems.

2. Process modelling for performances continuous improvement: In his book, (Gramdi, 2013) proposes a "meta-concept" similar to the process approach. He believes that each process can be modelized as a pipe which can be optimized by playing on its characteristics: its length, its crosssection, its thickness, its porosity. Gramdi proposal has caught our attention because of its approach, a priori simplistic, but which proves to be global because it is systemic, fractal, adaptive and evolutionary. The current $\mathrm{OE}$ methodologies allow to act on each of the pipe characteristics: the A allows to reduce the length of the pipe and, the LSS allows to reduce the section and length of the pipe (Table 4). Our second assumption will be to prioritize the current methodologies that allow to continuously reduce the length, thickness, cross section and porosity of a pipe, thus allowing to continuously improve the performance of a process, of an organization.

3. Operational excellence according to Girard and Jombart: The synergy solution, that we will propose, aims OE as defined operationally and managerially by (Girard, 2017) and (Jombart, 2016). To achieve this, every organization will have to be evaluated on five dimensions: the QCDSE. Our third assumption will be to propose a synergy solution compliant with the QCDSE criteria.

4. Speed of deployment: One of the lessons we have learned from our experience in systems engineering is that stakeholders commitment, simplicity and efficiency of a solution are essential factors to guarantee the success of an $\mathrm{OE}$ approach involving the entire organization. Our fourth assumption will be to focus on a synergy solution with the most reduce deployment time possible. The results will be available quickly, periodically, and within everyone's reach. To reach this goal, we will focus on the data science which should allow a relevant, global and efficient decision-making.

The four (4) hypotheses stated above, associated with the LAS solution. Table 4, below, highlights the completeness and complementarity of the LAS solution. It has been established thanks to the work of (Morris, 2012), (Munteanu, 2017) and (Ghavami, 2008).

Table 4. LSS and $A$ for the solution LAS.

\begin{tabular}{|c|c|c|}
\hline Methodology & Lean Six Sigma & Agility \\
\hline Proposed in & 2002 & 2001 \\
\hline Goal & $\begin{array}{l}\text { - Stabilize and Simplify - } \\
\text { Reduce variability (Satisfying customer } \\
\text { requirements) } \\
\text { Remove waste (Improving } \\
\text { productivity) }\end{array}$ & $\begin{array}{l}\text { - Prioritize - } \\
\text { Schedule and cadence the processing of } \\
\text { customer needs } \\
\text { (Satisfy the customer requirements, } \\
\text { improving productivity) }\end{array}$ \\
\hline Tools & $\begin{array}{l}\text { DMAIC, DMADV, DFSS (statistical } \\
\text { measures of variability) } \\
\text { Ishikawa Diagram, } 5 \mathrm{~W}, 5 \mathrm{~S} \text {, Kanban, } \\
\text { SIPOC, VSM, Poka Yoke (visual } \\
\text { measures) }\end{array}$ & $\begin{array}{l}\text { Kanban Workflow, scrum approach, } \\
\text { Project backlog, sprint backlog, sprint } \\
\text { (iterative and incremental practices). }\end{array}$ \\
\hline Focus & Performance improvement & System \\
\hline Implementation & Bit difficult & Easy \\
\hline Direct results & $\begin{array}{l}\text { Combined } \\
\text { Lean and Six Sigma results. }\end{array}$ & Fast design \\
\hline Indirect results & $\begin{array}{l}\text { Less variation, less waste, less } \\
\text { inventory, performance measurement } \\
\text { (variability and flux), quality } \\
\text { improvement. }\end{array}$ & $\begin{array}{l}\text { Transparency, collective intelligence, } \\
\text { Reduce any process time and cost } \\
\text { overload, continuous inspection, improve } \\
\text { flexibility }\end{array}$ \\
\hline Limits & Combined Lean and Six Sigma limits & $\begin{array}{l}\text { Quality often side lined, Less time for } \\
\text { documentation, Requires the customer's } \\
\text { availability. }\end{array}$ \\
\hline
\end{tabular}




\section{CONCLUSION}

In this article, we have presented a state of the art of current $\mathrm{OE}$ methodologies. We have started, first of all, by highlighting their growing importance through a literature review. Then, we have given the definition and the singularities of each of these methodologies. We have taken the time to contextualize our works by detailing our objectives through the Girard and Jombart definitions. Secondly, we have presented two synergy solutions proposed by the managerial and scientific literature in line with our objectives. From these works, four (4) hypotheses, the LAS synergy solution and then the five-dimensional QCDSE evaluation criteria, which will serve as a basis, in our future work, for proposing a global operational excellence solution for systems engineering: from embedded systems engineering to Internet of Things systems engineering (Hehenberger et al. 2016) via The loop of operational excellence.

We have chosen a synergy solution (tools and methodology) with iterative approach in order to make possible its adaptability according to the complexity of the systems to be designed (from embedded systems to IoT systems), the scope of application concerned (industrial product or service) and the intended weighting of each of the QCDSE evaluation criteria. We will detail this proposal in a future paper.

\section{ACKNOWLEDGMENTS}

This article has been written with the support of the Department for Lifelong Learning of UNIVERSITE DE TECHNOLOGIE DE COMPIEGNE. We would like to thank all the people who have allowed us to propose this paper.

\section{REFERENCES}

Badwe, S. and Erkan T.E. (2018). "A Taxonomy of Lean Six Sigma and Agile Methodologies used in Software Development", International Journal of Engineering Research and Technology. ISSN 09743154 Volume 11, Number 5, pp. 725-753.

Baxter, R. (2015), Operational Excellence Handbook: A Must Have for Those Embarking On a Journey of Transformation and Continuous Improvement, Lulu.com, ISBN 9781329184329.

Beck, K., Grenning, J., Martin, R., Beedle, M., Highsmith, J., Mellor, S., Van Bennekum, A., Hunt, A., Schwaber, K., Cockburn, A., Jeffries, R., Sutherland, J., Cunningham, W., Kern, J., Thomas, D., Fowler, M., Marick, B. (2001), https://agilemanifesto.org/iso/fr/manifesto.html

Blanchard, B. S. (2016). Systems engineering management. $5^{\text {th }}$ edition, Wiley. ISBN 9781119047827.

Burton, H. O. and Pennotti, M. C. (2003). "The Enterprise Map: A System for Implementing Strategy and Achieving Operational Excellence”, Engineering Management Journal, Vol. 15, pp. 15-20.

Collins, J. (2001), Good To Great- Why some companies make the leap... and others don't. $37^{\text {th }}$ edition, Random House Business, ISBN 9780712676090.

George, M. (2002). Lean Six Sigma: Combining Six Sigma Quality with Lean Production Speed, McGraw-Hill Professional, ISBN 9780071385213.

Geracie, G and Eppinger, S. (2013). The Guide to the Product Management and Marketing Body of Knowledge: ProdBOK. $1^{\text {st }}$ edition, Product Management Educational Institute, ISBN 978098451850.

Gershon, M. (2010). “Choosing Which Process Improvement Methodology to Implement”. Journal of Applied Business \& Economics, Vol. 10 Issue 5, pp. 61-70.

Ghavami, P. (2008). Lean, Agile and Six Sigma Information Technology Management: New Stratagems to Achieve Perfection, Create Space Independent Publishing Platform, ISBN 9781440478123.

Girard, M. (2017). L'Excellence opérationnelle-L'arme secrète des Entreprises à Succès, Printed in Great Britain by Amazon, ISBN 9781521056646.

Goldratt, E (2014). The Goal: A Process of Ongoing Improvement, 3rd Revised Edition. North River Press, ISBN 9780884271956.

Gramdi, J. (2013). La Boucle Vertueuse de l'Excellence-Comment mettre harmonieusement en synergie le lean management, le six sigma et la théorie des contraintes pour enfin de vrais résultats en rupture, Lexitis Editions, ISBN 9782362331152.

Gubinelli, S., Cesarotti, V., Introna, V. (2019). "The evolution of Project Management (PM): How Agile, Lean and Six Sigma are changing PM”, The Journal of Modern Project Management. Special Issue: Vol 7 N³.

Hehenberger, P., Vogel-Heuser, B., Bradley, D., Eynard, B., Tomiyama, T., Achiche, S. (2016). "Design, Modelling, Simulation and Integration of Cyber Physical Systems: Methods and Applications", Computers in Industry, Vol. 82, pp. 273-289.

Hohmann, C. (2016) http://christian.hohmann.free.fr/index.php/synergie-tls-toc-lean-six-sigma. 
Huang, H.H. (2002). "Integrated production model in agile manufacturing systems". International Journal of Advanced Manufacturing Technology, Vol. 20 No 7, pp. 515-525.

INCOSE. (2015). INCOSE systems engineering handbook: a guide for system Life cycle processes and activities. John Wiley \& Sons.

ISO/IEC 15288. (2002). Systems engineering-system life cycle processes. International Standardization Organization/International Electrotechnical Commission.

ISO 9000. (2017). ISO 9000 Quality Systems Handbook: Increasing the Quality of an Organization's Outputs. $7^{\text {th }}$ edition, Routledge. ISBN 9781138188648.

Jombart, P. (2016). L'Excellence opérationnelle- Piloter l'entreprise 5.0, Edition l'Archipel, ISBN 978280981887-1.

Meyer, F. (2014). Appliquer le ToC Lean Six Sigma dans les services, Lexitis Editions, ISBN 9782362331299.

Morris, P. (2012). "The perfect process storm: Integration of CMMI, agile, and lean six sigma", CrossTalk Magazine: The Journal of Defense Software Engineering, pp. 39-45.

Munteanu, A. (2017). "Comparative Analysis between Lean, Six Sigma and Lean Six Sigma Concepts", Management and Economics Review, Vol. 2, Issue 1, pp. 78-89.

Nave, D. (2002). "How To Compare Lean and the Theory of Constraints", Quality Progress, Vol. 35, pp. 73-78.

O’Rourke, P. M. (2005). A Multiple-Case analysis of lean six sigma deployment and implementation strategies. MSc thesis, Department of Logistics Management, Air Force Institute of Technology, Air University, USA

Oakland, J.S. (2001). Total organizational excellence: Achieving world-class performance. Routledge, ISBN 978-0750652711.

Pacheco, D. (2015). “TOC, lean and six sigma: The missing link to increase productivity?" African Journal of Business Management, Vol 9 (12), pp. 513-520.

Porter, L.J. and Tanner, S.J. (2003), Assessing business excellence, $2^{\text {nd }}$ edition, Routledge, ISBN 9780750655170

Rossi, M., Cattaneo, L., Duigou, J., Terzi, S., Fugier-Garrel, S., Eynard, B. (2016). "Lean Product Development and the Role of PLM", 13th IFIP International Conference on Product Lifecycle Management (PLM), pp. 183-192.

Sreedharan, R. V., Raju, R. (2016). "A systematic literature review of Lean Six Sigma in different industries". International Journal of Lean Six Sigma, Vol. 7, N4, pp. 430-466.

Verma, D., Pennotti, M., Buede, D., Farr, J. (2003), “The system design and operational effectiveness (SDOE) Program: Experiences and Lessons learned”, DS31: Proceedings of ICED 03, the 14th International Conference on Engineering Design, Stockholm.

Volck, N. (2009). Déployer et exploiter Lean six sigma. Editions d'Organisation- Groupe Eyrolles, ISBN 978-2212-54334-6.

Waal, A. De (2011), “Creating High Performance Organisations: The Determining Factors”, Maastricht School of Management, Working Paper No. 2011/10. 


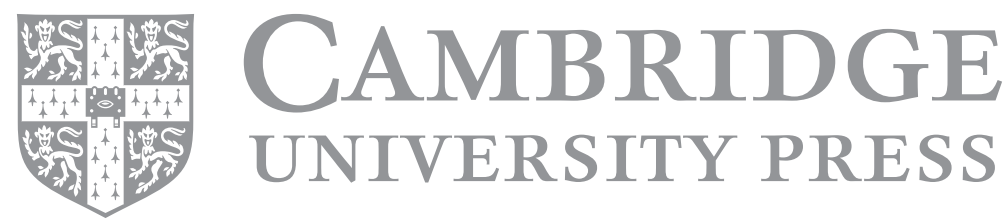

